\title{
La intervención del juez en la donación de órganos de donante vivo, un acto de jurisdicción voluntaria
}

\author{
Judicial intervention in organ donation from living donors. An \\ act of voluntary jurisdiction.
}

\begin{abstract}
Resumen
Junto a los trasplantes de órganos procedentes de donante fallecido, cada vez tienen más importancia los trasplantes procedentes de donante vivo. La legislación española, al igual que la de otros países de nuestro entorno, prevé que el consentimiento para este tipo de donación se formalice en presencia judicial. A continuación nos referimos a la normativa reguladora de esta intervención judicial que pretende sustancialmente garantizar el carácter libre, informado y desinteresado del consentimiento del donante, contribuyendo así a dar transparencia y seguridad al sistema de donación. Recordaremos brevemente la evolución legislativa para después analizar los requisitos generales de este tipo de actuación. Finalmente nos referiremos a los trámites seguidos en sede judicial para la formalización del consentimiento; trámites que concluyen con la redacción del denominado documento de cesión. Estos trámites se configuran como un acto de la denominada jurisdicción voluntaria, tipo de actuación judicial caracterizado por la ausencia de conflicto entre partes y por la flexibilidad procesal.
\end{abstract}

Palabras clave: Trasplante de órgano. Donante vivo. Intervención judicial. Jurisdicción voluntaria. Documento de cesión.

\begin{abstract}
Along with transplants of organs from deceased donors, are increasingly important transplants from living donors. The Spanish law, like that of other neighboring countries, provides that the statement of this consent should be formulated under the supervision and with the approval of a Court.

Ahead we refer to the rules governing this judicial intervention, intended to substantially ensure the full and free, informed and non-profit donor consent, so contributing to enhance transparency and legal certainty of the donation. Briefly recall legislative developments so as then to analyse the general requirements for such action.

Finally, we refer to the procedures followed in the courts for the formalization of Consent; procedures that end with the drafting of the document called assignment. These procedures are set up as an act of so-called Voluntary Jurisdiction, type of judicial action characterized by the absence of conflict between Parties and procedural flexibility.
\end{abstract}

Key words: Organ transplant. Live donor. Judicial proceeding. Voluntary jurisdiction. Assignment Document.

\section{Introducción}

"La donación en vida coexiste con la donación tras el fallecimiento en la mayoría de los Estados miembros [de la Unión Europea]. La donación en vida ha ido evolucionando a lo largo de los años de manera que se pueden obtener buenos resultados incluso cuando no existe una relación genética entre el donante $y$ el receptor. El donante vivo debe ser evaluado ade- cuadamente para determinar su idoneidad para la donación y minimizar el riesgo de transmisión de enfermedades al receptor. Además, los donantes vivos corren riesgos relacionados tanto con las pruebas para determinar su idoneidad como con el propio procedimiento de obtención del órgano. [...] Las donaciones en vida han de hacerse de modo que se minimice el riesgo físico, psicológico y social para cada donante y receptor, y que no comprometa la

\section{S. Ibáñez Molinero}

Magistrado. Juzgado de Primera Instancia núm. 5 de Granada

Correspondencia:

Santiago Ibáñez Molinero

E-mail: santibmo@hotmail.com
Fecha de recepción: 16.JUN.2015

Fecha de aceptación: 29.JUN.2015 
confianza pública en el sistema sanitario. El posible donante vivo tiene que poder decidir libremente sobre la base de toda la información pertinente, y debe ser informado de antemano sobre la finalidad y la naturaleza de la donación, sus consecuencias y sus riesgos. En este contexto, y para garantizar el respeto de los principios por los que se rige la donación, debe garantizarse la mayor protección posible de los donantes vivos. Una información completa, una evaluación adecuada y un seguimiento apropiado son medidas reconocidas internacionalmente destinadas a proteger a los donantes vivos y que también contribuyen a garantizar la calidad y la seguridad de los órganos."

(Exposición de motivos de la Directiva 2010/53/UE del Parlamento Europeo y del Consejo, de 7 de julio de 2010, sobre normas de calidad y seguridad de los órganos humanos destinados al trasplante.)

Como vemos, desde la propia Unión Europea se advierte de la necesidad de que los estados miembros regulen la donación de órganos entre personas vivas estableciendo una serie de garantías. Uno de los fines fundamentales de tal regulación ha de ser la protección del donante vivo, garantizando que su consentimiento sea libre y suficientemente informado. Pues bien, entre las garantías que la legislación española establece a tal efecto está la intervención del juez en el proceso de donación de órganos procedentes de donante vivo. Como veremos a continuación, la actuación que se realiza ante el juez es una comparecencia del donante y de los profesionales médicos responsables de la operación; se pretende, sencillamente, que el juez constate que el donante tiene suficiente capacidad, que está informado y que otorga su consentimiento de manera libre.

El artículo 117.3 de la Constitución Española atribuye a los juzgados y tribunales el ejercicio de la potestad jurisdiccional juzgando y haciendo ejecutar lo juzgado. A continuación, en el apartado cuarto, dicho artículo establece que los juzgados y tribunales no ejercerán más funciones que las señaladas en el apartado anterior y las que expresamente les sean atribuidas por ley en garantía de cualquier derecho. En esta última referencia es donde debemos ubicar la intervención del juez en el proceso de donación de órganos entre vivos: una función de garantía de derechos individuales. La atribución de esta función a los jueces no es única del ordenamiento español, existiendo otros países de nuestro entorno, como Francia o Alemania, cuya legislación también prevé la intervención del juez en la autorización de la donación de órganos procedente de donantes vivos.

\section{Marco legislativo}

Debemos referirnos en primer lugar a la Ley 30/1979, de 27 de octubre, sobre extracción y trasplante de órganos. El artículo 4 de dicha ley establece los requisitos generales para lo que literalmente denomina la "obtención de órganos procedentes de un donante vivo, para su ulterior injerto o implantación en otra persona". Entre tales requisitos, señala el siguiente: que el donante otorgue su consentimiento de forma expresa, libre y consciente, debiendo manifestarlo, por escrito, ante la autoridad pública que reglamentariamente se determine, tras las explicaciones del médico que ha de efectuar la extracción.

El Real Decreto 426/1980, de 22 de febrero, desarrolló esta ley, señalando que esta autoridad ante la que el donante vivo debía formalizar su consentimiento era precisamente el juez encargado del Registro Civil.

El Real Decreto 2070/1999, de 30 de diciembre, por el que se regulan las actividades de obtención y utilización clínica de órganos humanos y la coordinación territorial en materia de donación y trasplante de órganos y tejidos, derogó ese RD 426/1980, pero mantuvo esta atribución al encargado del Registro Civil.

Este RD es derogado a su vez por la norma reglamentaria vigente: el Real Decreto 1723/2012, de 28 de diciembre, por el que se regulan las actividades de obtención, utilización clínica y coordinación territorial de los órganos humanos destinados al trasplante y se establecen requisitos de calidad y seguridad. En su artículo 8 se regulan los requisitos para la obtención de órganos de donante vivo, si bien las normas procedimentales han pasado ahora a recogerse en la muy reciente Ley de Jurisdicción Voluntaria a la que a continuación nos referimos. Entre tales requisitos, a los que nos referiremos a continuación, se sigue regulando la formalización del consentimiento del donante ante la autoridad judicial. La novedad es que la competencia pasa del juez encargado del Registro Civil al juez de Primera Instancia de la localidad donde haya de efectuarse la extracción o el trasplante. En la práctica, este cambio puede producir inconvenientes de coordinación: el encargado del Registro Civil es un solo juez en cada partido judicial; sin embargo, los jueces de primera instancia son varios, muchos en las grandes ciudades. Los responsables médicos que deben intervenir en la actuación judicial suelen desear, razonablemente, coordinarse con un solo juzgado, para poder así establecer un protocolo de actuación uniforme. La competencia en turno rotatorio de todos los jueces de primera instancia de 
la localidad correspondiente puede dificultar dicha coordinación. Este eventual inconveniente puede solucionarse en la práctica mediante el establecimiento en cada partido judicial de una norma específica de reparto de asuntos judiciales que atribuya a un solo juez de primera instancia el conocimiento de este tipo de actuaciones. Así se ha hecho ya en varios partidos judiciales, como es el caso de Granada, Sevilla o Córdoba. Pero siempre esta decisión depende en primera instancia de las Juntas de Jueces respectivas y de la posterior autorización del Tribunal Superior de Justicia de la comunidad autónoma.

El día 2 de julio de 2015 se publicó en el BOE la Ley de Jurisdicción Voluntaria, que en el Capítulo X de su Título II, artículos 78 a 80, es ahora la norma que recoge el procedimiento judicial para autorizar la extracción de órganos de donante vivo. Dicha regulación procesal es sustancialmente igual a la del citado Real Decreto de 1723/2012.

\section{Requisitos para la obtención de órganos de donante vivo}

Como hemos visto, tales requisitos se recogen en el artículo 8 del RD 1723/2012. Podemos sistematizarlos resumidamente:

- Requisitos personales del donante:

- Debe ser mayor de edad; no se autoriza la obtención de órganos de menores de edad ni siquiera con el consentimiento de sus padres o tutores.

- Debe gozar de plenas facultades mentales y de un estado de salud adecuado.

- Requisitos del órgano y su destino:

- Debe tratarse de un órgano, o parte de él, cuya obtención sea compatible con la vida y cuya función pueda ser compensada por el organismo del donante de forma adecuada y suficientemente segura.

- El órgano extraído del donante vivo debe ser destinado al trasplante a una persona determinada con el propósito de mejorar sustancialmente su pronóstico vital o sus condiciones de vida (dicho de otra manera, no se permite la donación para la creación de "bancos de órganos").

- Información previa al donante: el donante habrá de ser informado previamente de las consecuencias de su decisión y en particular de los riesgos, para sí mismo o para el receptor, así como de las posibles contraindicaciones.

- Expresión del consentimiento: el donante debe otorgar su consentimiento de forma expresa, libre, consciente y desinteresada. Esta última referencia debe entenderse como desinterés económico, lógicamente, poniéndolo en relación con la exigencia del artículo 7 que prevé la necesaria gratuidad de las donaciones.

Con el fin de garantizar que se cumplen estos requisitos, la norma que comentamos establece la necesidad de seguir unos trámites. Podemos distinguir en dos momentos sucesivos: a) las actuaciones en el ámbito de la administración médico-hospitalaria, y b) la intervención judicial.

En el ámbito médico, la norma prevé en especial las siguientes garantías: 1) la preceptiva emisión de un informe del comité de ética correspondiente; 2) un examen sobre el estado de salud físico y mental del donante, realizado por un médico cualificado que además ha de ser distinto de aquellos que vayan a efectuar la extracción y el trasplante; 3) la información al donante sobre los riesgos inherentes a la intervención, las consecuencias previsibles de orden somático o psicológico, las repercusiones que pueda suponer en su vida personal, familiar o profesional, así como de los beneficios que se esperan del trasplante y los riesgos potenciales para el receptor.

El cumplimiento de tales requisitos se plasma en un certificado médico que hará necesariamente referencia al estado de salud, a la información facilitada y a la respuesta y las motivaciones libremente expresadas por el donante y, en su caso, a cualquier indicio de presión externa a este. Y que incluirá la relación nominal de otros profesionales que puedan haber colaborado en tales tareas con el médico que certifica.

\section{La intervención del juez: un acto de jurisdicción voluntaria}

El RD 1723/2012, al que nos estamos refiriendo calificaba de manera expresa la actuación judicial en este ámbito como un acto de jurisdicción voluntaria. Para encontrar una definición legal de este concepto, debíamos acudir al artículo 1811 de la Ley de Enjuiciamiento Civil de 1881, pues la actual Ley de Enjuiciamiento Civil mantuvo la vigencia de los preceptos de la anterior relativos a la jurisdicción voluntaria. Dicho artículo, en su terminología decimonónica, 
dice así: "Se considerarán actos de jurisdicción voluntaria todos aquellos en que sea necesaria o se solicite la intervención del Juez sin estar empeñada ni promoverse cuestión alguna entre partes conocidas y determinadas". Dicho en otras palabras: son actos de jurisdicción voluntaria aquellas actuaciones judiciales en las que no existen partes con intereses contrapuestos. En la jurisdicción voluntaria, el juez interviene, pero sin ejercer su habitual función de resolver cuestiones litigiosas. Entendemos que, al calificar la intervención del juez en el proceso de donación de órganos procedentes de donante vivo como un acto de jurisdicción voluntaria, el legislador ha querido aclarar que no deberán aplicarse las normas procesales que regulan los distintos tipos de juicios. La jurisdicción voluntaria se caracteriza por la ausencia de formalidades procesales y la búsqueda de la facilidad en el trámite. Debemos adelantar que lo que se pretende con la intervención judicial es sobre todo garantizar que el donante consiente efectivamente la cesión del órgano que se le ha de extraer, que para tomar esa decisión ha sido suficientemente informado por los médicos, y que dicho consentimiento es libre y desinteresado, como antes decíamos.

La recientemente publicada Ley de Jurisdicción Voluntaria, en su artículo 1 , recoge una definición similar de lo que debe entenderse por procedimientos de este tipo: "Se consideran expedientes de jurisdicción voluntaria a los efectos de esta Ley todos aquellos que requieran la intervención de un órgano jurisdiccional para la tutela de derechos e intereses en materia de Derecho civil y mercantil, sin que exista controversia que deba sustanciarse en un proceso contencioso".

\section{Inicio del procedimiento judicial: solicitud ante el juzgado}

- Persona que puede presentar la solicitud: el propio donante, el director del centro sanitario en que vaya a efectuarse o la persona en quien delegue.

- Contenido: la norma no prevé unos requisitos formales estrictos para esta solicitud. Basta con que en la misma se expresen:

- Las circunstancias personales y familiares del donante.

- El objeto de la donación.

- El centro sanitario en que ha de efectuarse la extracción.

- La identidad del médico responsable del trasplante.
- Documentos que han de acompañarse a la solicitud: solo se exige la aportación del certificado médico sobre la salud mental y física del donante al que antes hemos hecho referencia.

\section{Comparecencia ante el juzgado. Sujetos intervinientes}

Una vez repartida la solicitud al juzgado correspondiente, sin más trámite, se convoca a una comparecencia en la que deben intervenir las siguientes personas: 1) evidentemente, el donante; 2) también evidentemente, el juez, debiendo estar presente también el secretario judicial, aunque la norma lo especifique, para dar fe de lo que se actúe; 3) el médico responsable de la extracción del órgano y el médico que vaya a realizar el trasplante (nada impide que sea un mismo profesional); 4) el médico que ha realizado el informe sobre la situación mental y física del donante a que antes nos hemos referido; y 5) la autoridad médica a la que corresponda dar la conformidad para la intervención según la autorización administrativa obtenida por el centro correspondiente.

El artículo 79 de la Ley de Jurisdicción Voluntaria establece de modo expreso que para estas actuaciones no es necesaria la intervención de abogado ni procurador; si bien, el artículo 3 prevé con carácter general que en aquellos actos -como es el casoen que la intervención de abogado y procurador no es necesaria, podrá ser voluntaria a decisión del interesado.

Planteamos la cuestión sobre la posible intervención de otros dos sujetos:

- El receptor del órgano: en general, en los denominados actos de jurisdicción voluntaria, conforme a los artículos 3 y 17 de la Ley de Jurisdicción Voluntaria (antes el artículo 1813 de la LEC), se prevé la posibilidad de intervención de aquellas personas que tengan interés legítimo en el asunto de que se trate. Es obvio que el receptor tiene tal interés y por tanto no puede negársele, si lo desea, ser oído en el expediente. Sin embargo, aunque donante y receptor comparezcan juntos en el juzgado (caso frecuente en la práctica, dada la usual relación de parentesco entre ambos), estimamos necesario que en algún momento el juez oiga al donante sin la presencia del receptor. Se trata de que el donante pueda expresarse con total libertad, manifestando sus dudas si las tuviere. Debe descartarse cualquier riesgo 
de que el donante actúe bajo presión, aunque simplemente sea de tipo emocional.

- El ministerio fiscal: también con carácter general, la vieja Ley de Enjuiciamiento Civil de 1881 preveía en su artículo 1815 que se oirá al ministerio fiscal cuando la solicitud promovida afecte a los intereses públicos, y cuando se refiera a persona o cosa cuya protección o defensa competan a la Autoridad. Aunque podía estimarse que en la donación de órganos existe un interés público que justificaría la intervención del fiscal, mi criterio ya era que la falta de previsión expresa sobre su actuación en esta comparecencia no se debía a un olvido del legislador, y que por tanto no procedía convocarle ni darle audiencia. Esta postura parece más clara tras la actual redacción del artículo 4 de la nueva Ley de Jurisdicción Voluntaria, que únicamente prevé la intervención del ministerio fiscal, con carácter general en este tipo de procedimientos de jurisdicción voluntaria, "cuando afecten al estado civil o condición de la persona o esté comprometido el interés de un menor o una persona con capacidad modificada judicialmente, y en aquellos otros casos en que la ley expresamente así lo declare", sin referencia ya a ese criterio del "interés público".

\section{Desarrollo de la comparecencia}

El objeto de esta comparecencia ante el juez, como hemos venido diciendo, es sustancialmente constatar que el donante es capaz para prestar su consentimiento, que está suficientemente informado, y que otorga su consentimiento de manera expresa y libre, sin que se aprecien datos que permitan sospechar la existencia de presiones o de ofrecimientos económicos. Se debe por tanto oír al donante, sin ningún tipo de formalismo, preguntándole sobre estos extremos, e interviniendo los profesionales médicos para completar -si es necesario- la información que ya se le ha suministrado de antemano sobre la intervención quirúrgica.

Oído al donante, dice la actual Ley de Jurisdicción Voluntaria que "si alguno de los asistentes dudara de que el consentimiento para la obtención se hubiese otorgado de forma expresa, libre, consciente y desinteresada, podrá oponerse a la donación". La anterior redacción contenida en el citado artículo 8 del RD $1723 / 2012$ decía literalmente que estos sujetos intervinientes en la comparecencia podría oponerse "eficazmente" a la donación. Parecía, pues, que bastara con que uno de los profesionales que están presentes planteara de manera expresa esas dudas para que el consentimiento no pudiera ser validado judicialmente. La eliminación de la expresión "eficazmente" parece dar al juez la posibilidad de autorizar la donación aun existiendo las referidas dudas expresas de alguno de los profesionales intervinientes, valorando lo razonable o no de tales dudas.

Si el donante manifiesta su conformidad y no se plantean dudas sobre su capacidad, libertad y desinterés, se firma por el donante y todos los intervinientes el acta que documenta lo que se ha manifestado por unos y otros. En la práctica, pues, el acta de la comparecencia es el documento que la ley llama "documento de cesión del órgano". De dicho documento se entrega copia al donante. En dicha acta debe constar que el donante puede revocar su consentimiento en cualquier momento antes de la intervención sin sujeción a formalidad alguna y sin que ello dé lugar a ningún tipo de indemnización. En la actual Ley de Jurisdicción Voluntaria (que -reiteramos- entra en vigor en este mes de julio de 2015) ya no se hace referencia a que entre la firma del acta de cesión y la práctica de la extracción del órgano deba existir un plazo mínimo; plazo que el Real Decreto 1723/2012 fijaba en veinticuatro horas. No obstante, entendemos que es razonable que exista un plazo razonable para no hacer ilusoria la posibilidad de revocación del donante. Debemos señalar que en la práctica dicho plazo siempre es bastante superior.

Finaliza aquí la intervención judicial. A partir de ahí, con ese acta que documenta la expresión del consentimiento del donante, si no ha existido revocación, puede practicarse la intervención. Como vemos, no existe propiamente una autorización judicial. Tras la comparecencia no ha de dictarse ninguna resolución por parte del juez para autorizar el trasplante, ni realizar ningún otro trámite judicial.

Los autores declaran no tener ningún conflicto de intereses. 


\section{Bibliografía}

- López del Moral JL. (Magistrado. Presidente de la Audiencia Provincial de Cantabria). Bases legales de la donación de vivo. Revista de la Sociedad Española de Nefrología. 2010;30 (Supl 2).

- Pradilla Gordillo E. (Magistrado encargado del Registro Civil de Sevilla). El encargado del Registro Civil en

su función de garante del derecho fundamental a la protección a la salud: su intervención en el proceso de donación de órganos y tejidos entre vivos. En: Consejo General del Poder Judicial. Estudios de Derecho Judicial. 2006;(98). 